раздел ФИЗИКА

УДК 53.087.22+661.7

DOI: 10.33184/bulletin-bsu-2020.2.5

ВИЗУАЛИЗАЦИЯ ЕДИНИЧНЫХ МОЛЕКУЛ АСФАЛЬТЕНОВ

(ㄱ И. С. Кутлубаев ${ }^{1}$, Т. И. Шарипов ${ }^{1}$, М. Ю. Доломатов ${ }^{1}$, Т. Н. Нурахметов ${ }^{2}$, Ж. М. Салиходжа' ${ }^{2}$ Р. 3. Бахтизин ${ }^{1}$

\author{
${ }^{1}$ Башкирский государственный университет \\ Россия, Республика Башкортостан, 450076 г. Уфа, ул. Заки Валиди, 32. \\ ${ }^{2}$ Евразийский Национальный университет им. Л. Н. Гумилева \\ Республика Казахстан, 010008 г. Астана, ул. Сатпаева, 2.
}

Email: k.ilshat.95@gmail.com

\begin{abstract}
С помощью атомно-силовой микроскопии в атмосфере воздуха были исследованы асфальтены, выделенные из гудрона. В результате проведенных исследований получены АСМ-изображения, на которых наблюдается топография мономолекулярного слоя асфальтенов. Визуализированы как единичные молекулы, так и кластеры асфальтенов. Измерены размеры этих молекул и кластеров. Проанализированы и сопоставлены два метода нанесения пленок асфальтенов.
\end{abstract}

Ключевые слова: асфальтены, атомно-силовая микроскопия, поверхность, подложка, молекула.

Асфальтены - высокомолекулярный компонент нефти, состоящий на 90-95\% из углеводорода [1]. В молекулу асфальтена, кроме углерода, водорода, кислорода и азота, входит и сера. Так же, асфальтены, растворимы в сероуглероде, в тетрахлоруглероде и в ароматических углеводородах. Однако они не растворяются в низкокипящих алканах. По некоторым данным строение молекул зависит от месторождения нефти, способа выделения асфальтенов, а так же от растворителя [2-5].

Развитие современных технологий открывает большую возможность в получении качественных и точных данных в изучении поверхностей наномасштабных размеров. В связи с этим появляются новые возможности изучения строения и наблюдения протекания некоторых процессов.

Одним из перспективных инструментов, является атомно-силовой микроскоп (АСМ), изобретенный Гердом Биннигом, Кельвином Куэйтом и Кристофером Гербером в 1982 г. Достоинством данного метода исследования является его сверхвысокая разрешающая способность, которая составляет порядка 0.1-1 нм.

Точность измерений, проводимых при помощи АCM, определяется значительным числом факторов, как аппаратурных, связанных с конструктивными особенностями узлов микроскопа, так и методических, обусловленных выбором параметров режима сканирования. Для выявления искажений той или иной природы и исключения их влияния на результат эксперимента созданы соответствующие рекомендации. Но даже выполнение всех рекомендуемых операций не гарантирует того, что источником дефектов не станет само состояние поверхности образцов. Поверхность может быть загрязненной, обладать кривизной, испытывать адгезию при взаимодействии с материалом зонда.
Целями исследования являются выявление наиболее оптимального метода нанесения пленки асфальтенов, экспериментально испробовав два различных метода нанесения; визуализация единичных молекул асфальтенов и их кластеров путем получения АСМ-изображений высокого разрешения; а также определение размеров отдельных молекул и кластеров.

Перед тем как исследовать образец, необходимо подобрать подложку. Для данных исследований подходит слюда, она обладает свойствами, подходящими для исследования надмолекулярных структур: обладает твердой поверхностью, слоистой структурой, а так же относительно гладкой поверхностью с перепадом высот менее 1 нм.

Далее необходимо приготовить образцы асфальтенов [6-8]. На результат влияет также место добычи нефти и способ выделения асфальтена из нефти. В нашем случае использовались асфальтены, выделенные из гудрона, и растворенные в толуоле в концентрации 1 г/л. Немаловажную роль играет способ нанесения образца на поверхность подложки. Мы выделили 2 основных метода нанесения пленки:

Метод Ленгмюра - Блоджетт. Гидрофобную подложку опускали в дистиллированную воду, затем на поверхность воды наносили каплю раствора асфальтена. После образования на поверхности воды нанослоя асфальтенов подложку, ориентированную в пространстве горизонтально, медленным вертикальным движением вверх извлекали из жидкости через нанослой. Затем извлеченную подложку сушили на воздухе в течение 2 ч. до полного высыхания с образованием пленки асфальтенов. АСМ-изображение поверхности пленки, полученной методом Ленгмюра - Блоджетт, представлено на рис. 1. 

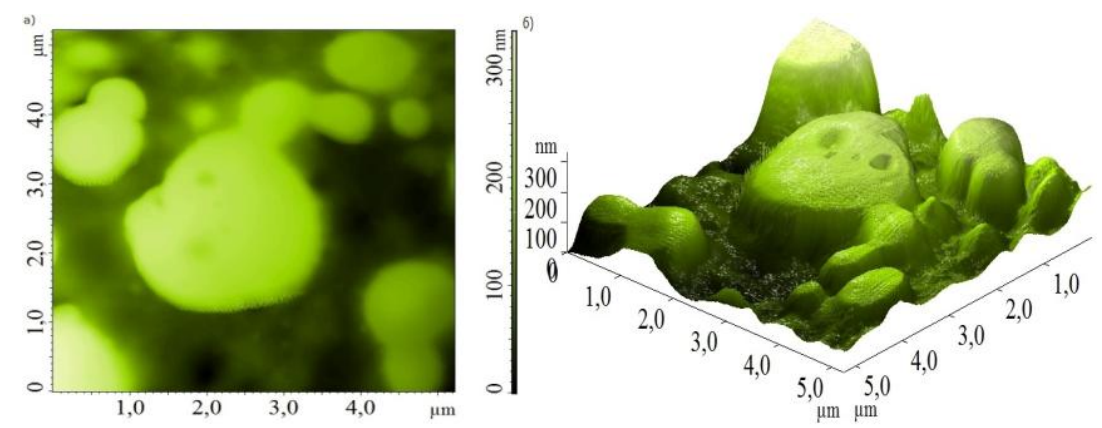

Рис. 1. а) АСМ-изображение пленки асфальтенов, полученной методом Ленгмюра - Блоджетт; б) 3D модель рис. $1 \mathrm{a}$.
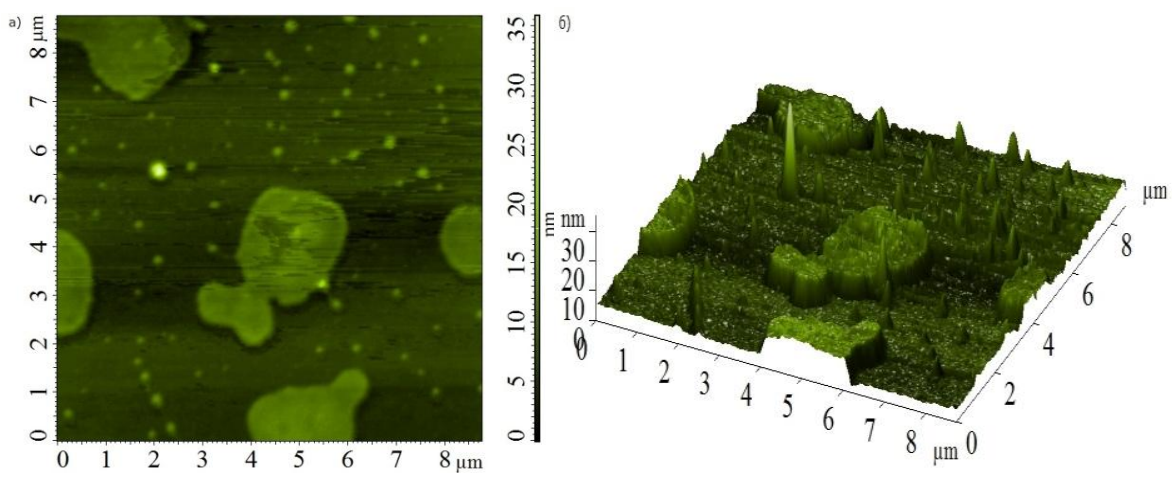

Рис. 2. а) АСМ-изображение пленки асфальтенов, полученной методом капельного нанесения; б) 3D модель рис. $2 \mathrm{a}$.

Метод капельного нанесения. Метод заключается в том, чтобы нанести небольшую каплю на существенную по размеру поверхность подложки и достичь максимально равномерного распределения по поверхности посредством центрифугирования. Далее после нанесения образца на поверхность подложки, необходимо дождаться полного высыхания и затвердевания поверхности. Это достигалось в закрытом сосуде и, находясь при комнатной температуре 60 мин. АСМизображение поверхности пленки, полученной методом капельного нанесения, представлено на рис. 2.

Анализируя АСМ-изображения поверхностей пленок, полученных двумя различными методами, видно, что при первом методе размеры объектов на
АСМ-изображении на порядок больше чем при втором методе, а так же наблюдается бОльшая поверхностная плотность нанесенных молекул и их кластеров. Имея общее представление о размерах единичных молекул, разумно будет выбрать метод, при котором размеры объектов на полученном АСМ-изображении близки по размеру с общепринятыми размерами: а именно, выбрать приоритетным метод капельного нанесения.

АСМ-исследование образцов проводилось в условиях сухой воздушной среды. При этом использовался зондовый микроскоп Интегра (NT-MDT Spectrum Instruments), сканирование проводилось в полуконтактном режиме.
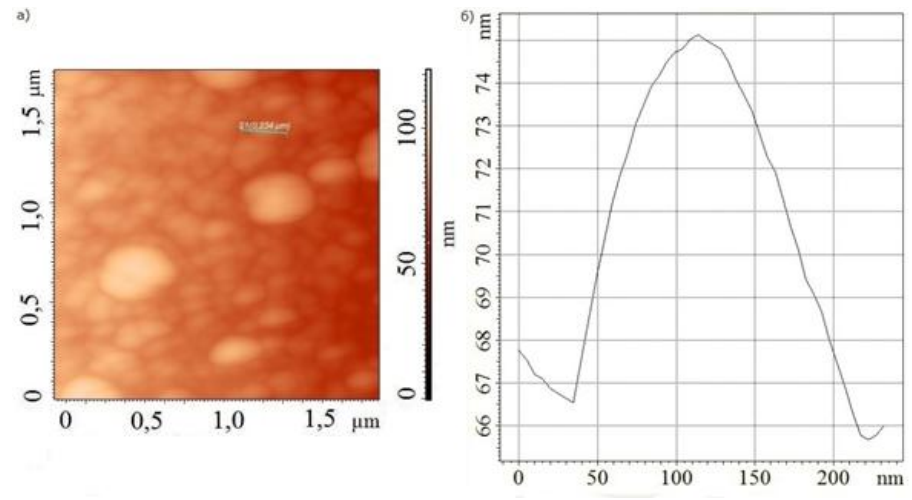

Рис. 3. а) АСМ-изображение с высоким разрешением пленки асфальтенов, полученной методом капельного нанесения; б) профиль сечения, выполненного по линии, показанной на puc. $3 \mathrm{a}$. 
На АСМ-изображении (рис. За) четко визуализируются объекты различных размеров. Допустимо предположить, что это кластеры и единичные молекулы асфальтенов. Для того чтобы удостовериться, выполним сечение по одному из небольших объектов. На рис. 36 показан профиль этого сечения. Как видно из профиля сечения, размеры объекта составляют в высоту около 8 нм и около 110 нм по латерали.

Визуально группу объектов на рис. 3 можно разделить на 2 подгруппы: в первую можно внести объекты, рассмотренные абзацем ранее, а во вторую - объекты с гораздо большими размерами: до 300 нм по латерали и высотой около 25 нм. В то же время объекты первой подгруппы значительно превосходят по количеству объекты второй подгруппы. Мы предполагаем, что объекты, которые мы отнесли ко второй подгруппе - это кластеры, образованные агрегированием довольно большого числа единичных молекул.

Таким образом, с помощью атомно-силовой микроскопии в атмосфере воздуха были исследованы асфальтены, выделенные из гудрона. В результате проведенных исследований получены АCMизображения, на которых наблюдается топография мономолекулярного слоя асфальтенов. Видны как единичные молекулы, так и кластеры асфальтенов. Измерены размеры этих поверхностных структур.

Работа выполнена при финансовой поддержке гранта РФФИ №17-42-020616, проекта №АР05132165 «Разработка технологии получения асфальтенов из нефтяного сырья в качестве органических полупроводников для наноэлектроники» Республики Казахстан и частично при поддержке гранта Республики Башкортостан молодым ученым, договор №29ГР (2019 г.).

\section{ЛИТЕРАТУРА}

1. Барская Е. Е., Ганеева Ю. М., Юсупова Т. Н., Охотникова Е. С., Романов Г. В. Роль различных типов асфальтенов в формировании структуры высоковязких нефтей // Химия нефти и газа: мат-лы IX Межд. конф. Томск: изд-во ИОА CO PAH, 2015. C. 454-460.

2. Сергиенко С. Р., Таимова Б. А., Талалаев Е. И. Высокомолекулярные неуглеводородные соединения нефти. М.: Наука. 1979. 269 с.

3. Поконова Ю. В. Химия высокомолекулярных соединений нефти. Л.: изд-во ЛГУ,1980. 171 с.

4. Бейко О. А., Головко А. К., Горбунова Л. В., Камьянов В. Ф. Химический состав нефтей Западной Сибири. Новосибирск: Наука, Сиб. отд-е, 1988. 288 с.
5. У Угер Ф. Г., Андреева Л. Н. Фундаментальные аспекты химии нефти. Природа смол и асфальтенов. Новосибирск: Наука, 1995. 192 с

6. Шарипов Т. И., Бахтизин Р. 3., Доломатов М. Ю., Шуткова С. А., Нурахметов Т. Н., Салиходжа Ж. М., Бадретдинов Б. Р. Исследование надмолекулярной структуры нефтяных асфальтенов // Бутлеровские сообщения. №3. Т. 57. 2019. C. 99-104.

7. Sharipov T. I., Dolomatov M. Y., Bakhtizin R. Z. The study of supramolecular structure of asphaltenes by atomic force microscopy // IOP Conf. Series: Materials Science and Engineering 443 (2018) 012028.

8. Шарипов Т. И., Акбутин Г. Д., Доломатов М. Ю., Бахтизин Р. 3. Особенности надмолекулярной структуры асфальтенов, выделенных из остатков термокрекинга // Электротехнические и информационные комплексы и системы. 2018. Т. 14. №2. С. 106-112.

9. Мургич Х. Молекулярное моделирование фракций асфальтенов и смол в нефтях //Физико-химические свойства дисперсных систем и нефтегазовые технологии. Ижевск, 2007. С. 580.

10. Бикинеев В. А., Нигматуллин Р. Г., Сыркин А. М. Использование очищающего комплекса для деасфальтизации нефтяного сырья // Башкирский химический журнал. 2011. №2. C. 185-189.

11. Ганеева Ю. М., Юсупова Т. Н., Романов Г. В. Асфальтеновые наноагрегаты: структура, фазовые превращения, влияние на свойства нефтяных систем // Успехи химии. 2011. T. 80. №10. C. 1050 .

12. Доломатов М. Ю., Телин А. Г., Силин М. А. Нефтепромысловая химия. Физико-химические основы направленного подбора растворителей асфальто-смолопарафиновых отложений: учеб. пособие для вузов. М.: РГУ нефти и газа им. Губкина, 2011. 69 с.

13. Доломатов М. Ю., Унгер Ф. Г., Хайрудинов И. Р., Колбин М. А., Хашпер Л. М. Метод идентификации состава углеводородных нефтяных фракций и нефтяных составов. Томск: Препринт /ИХНТФ СО АН СССР, 1989. 47 с.

14. Доломатов М. Ю., Пестриков С. В., Юсупов Э. А., Александрова С. А. Асфальтосмолистые олигомеры. Применение и физико-химические свойства. М.: ЦНИИТЭнефтехим, $1992.70 \mathrm{c}$.

15. Зондовая НаноЛаборатория ИНТЕГРА. Проведение измерений.Руководство пользователя. НТ-МДТ, 2006. С. 340.

16. Коржов Ю. В., Орлов С. А. Агрегирование и коагуляция асфальтенов в пленке нефти: физические характеристики продуктов поверхностных отложений // Известия Томского политехнического университета. Инжиниринг георесурсов. 2016. Т. 327. №12. С . 62-74.

17. Лихацкий В. В. Исследование диэлектрических и структурных характеристик асфальтеносодержащих дисперсных систем: дисс. ... канд. техн. наук. М., 2010. 108 с.

18. Поконова Ю. В. Химические реакции асфальтенов. Л.: изд-во ЛТИ им. Ленсовета. 1984. 25 с.

19. Посадов И. А., Поконова Ю. В. Структура нефтяных асфальтенов. Л.: изд-во ЛТИ им. Ленсовета. 1977. 76 с.

20. Ширяева Р. Н., Бадикова А. Д. и др. Анализ элементного состава асфальтенов из остатков нефтей Приобского и Баклановского месторождений. // Вестник БашГУ. Т. 22. 2017. №2. C. 364-366. 
DOI: $10.33184 /$ bulletin-bsu-2020.2.5

\title{
VISUALIZATION OF SINGLE MOLECULES OF ASPHALTENES
}

\author{
(C) I. S. Kutlubaev ${ }^{1}$ *, T. I. Sharipov ${ }^{1}$, M. Yu. Dolomatov ${ }^{1}$, \\ T. N. Nurakhmetov ${ }^{2}$, Zh. M. Salikhodzha ${ }^{2}$, R. Z. Bakhtizin ${ }^{1}$ \\ ${ }^{1}$ Bashkir State University \\ 32 Zaki Validi Street, 450076 Ufa, Republic of Bashkortostan, Russia. \\ ${ }^{2}$ L. N. Gumilyov Eurasian National University \\ 2 Satpayev Street, 010008 Astana, Republic of Kazakhstan.
}

\begin{abstract}
*Email: k.ilshat.95@gmail.com
Recently, much attention has been paid to works in which organic materials are used as materials for electronics. This is due to the unique properties of the elements of organic electronics, which exhibit semiconductor properties, and the sizes of these elements that can be comparable with the size of the organic molecule. Promising materials for the elemental base in molecular electronics are asphaltenes. It is known that asphaltenes in oil disperse systems are contained in the form of supramolecular structures ranging in size from 1 to $1000 \mathrm{~nm}$, which enables considering asphaltenes as a promising object of nanotechnology. With the advent of atomic force microscopy, it became possible to study in depth objects of small size up to atomic scale. This research method is currently one of the main methods for studying the surface of macromolecules and supramolecular structures. A large number of experiments were conducted to determine the structure and properties of asphaltenes. With properly selected solution concentrations, environmental conditions, and microscope mode of operation, clusters of several individual asphaltene molecules can be visualized with ultra-high resolution. Asphaltenes isolated from the residue of thermal cracking were studied with the use of atomic force microscopy in an air atmosphere. Asphaltenes dissolved in toluene at different concentrations were deposited on the surface of the substrate by various methods in order to identify the best method that would produce AFM images of the highest quality. Asphaltenes have an increased tendency to associate and form supramolecular structures. As a result, it is difficult to visualize single molecules. The authors of the article obtained AFM images on which the topography of the monomolecular layer of asphaltenes is observed. Both single molecules and clusters of asphaltenes are visible. The sizes of these molecules and clusters are measured. The obtained data was analyzed and compared with the results of other researchers.
\end{abstract}

Keywords: asphaltenes, atomic force microscopy, asphalt resinous substances, sample, substrate, molecule.

Published in Russian. Do not hesitate to contact us at bulletin_bsu@mail.ru if you need translation of the article.

\section{REFERENCES}

1. Barskaya E. E., Ganeeva Yu. M., Yusupova T. N., Okhotnikova E. S., Romanov G. V. Khimiya nefti i gaza: mat-ly IX Mezhd. konf. Tomsk: izd-vo IOA SO RAN, 2015. Pp. 454-460.

2. Sergienko S. R., Taimova B. A., Talalaev E. I. Vysokomolekulyarnye neuglevodorodnye soedineniya nefti [High molecular weight non-hydrocarbon oil compounds]. Moscow: Nauka. 1979.

3. Pokonova Yu. V. Khimiya vysokomolekulyarnykh soedinenii nefti [Chemistry of high molecular weight oil compounds]. Leningrad: izd-vo LGU,1980.

4. Beiko O. A., Golovko A. K., Gorbunova L. V., Kam'yanov V. F. Khimicheskii sostav neftei Zapadnoi Sibiri [The chemical composition of oils of Western Siberia]. Novosibirsk: Nauka, Sib. otd-e, 1988.

5. Unger F. G., Andreeva L. N. Fundamental'nye aspekty khimii nefti. Priroda smol i asfal'tenov [Fundamental aspects of petroleum chemistry. The nature of resins and asphaltenes]. Novosibirsk: Nauka, 1995.

6. Sharipov T. I., Bakhtizin R. Z., Dolomatov M. Yu., Shutkova S. A., Nurakhmetov T. N., Salikhodzha Zh. M., Badretdinov B. R. Butlerovskie soobshcheniya. No. 3. Vol. 57. 2019. Pp. 99-104.

7. Sharipov T. I., Dolomatov M. Y., Bakhtizin R. Z. IOP Conf. Series: Materials Science and Engineering 443 (2018) 012028.

8. Sharipov T. I., Akbutin G. D., Dolomatov M. Yu., Bakhtizin R. Z. Elektrotekhnicheskie i informatsionnye kompleksy i sistemy. 2018. Vol. 14. No. 2. Pp. 106-112. 
9. Murgich X.Fiziko-khimicheskie svoistva dispersnykh sistem i neftegazovye tekhnologii. Izhevsk, 2007. Pp. 580.

10. Bikineev V. A., Nigmatullin R. G., Syrkin A. M. Bashkirskii khimicheskii zhurnal. 2011. No. 2. Pp. 185-189.

11. Ganeeva Yu. M., Yusupova T. N., Romanov G. V. Uspekhi khimii. 2011. Vol. 80. No. 10. Pp. 1050.

12. Dolomatov M. Yu., Telin A. G., Silin M. A. Neftepromyslovaya khimiya. Fiziko-khimicheskie osnovy napravlennogo podbora rastvoritelei asfal'to-smoloparafinovykh otlozhenii: ucheb. posobie dlya vuzov [Oilfield chemistry. Physico-chemical bases of the directed selection of solvents of asphalt-resin-paraffin deposits: textbook for universities]. Moscow: RGU nefti i gaza im. Gubkina, 2011.

13. Dolomatov M. Yu., Unger F. G., Khairudinov I. R., Kolbin M. A., Khashper L. M. Metod identifikatsii sostava uglevodorodnykh neftyanykh fraktsii i neftyanykh sostavov [Method for identifying the composition of hydrocarbon oil fractions and oil compositions]. Tomsk: Preprint /IKhNTF SO AN SSSR, 1989. 47 p.

14. Dolomatov M. Yu., Pestrikov S. V., Yusupov E. A., Aleksandrova S. A. Asfal'tosmolistye oligomery. Primenenie i fiziko-khimicheskie svoistva [Asphalt-resinous oligomers. Application and physico-chemical properties]. Moscow: TsNIITEneftekhim, 1992.

15. Zondovaya NanoLaboratoriya INTEGRA. Provedenie izmerenii. Rukovodstvo pol'zovatelya. NT-MDT, 2006. Pp. 340.

16. Korzhov Yu. V., Orlov S. A. Izvestiya Tomskogo politekhnicheskogo universiteta. Inzhiniring georesursov. 2016. Vol. 327. No. 12. Pp. 62-74.

17. Likhatskii V. V. Issledovanie dielektricheskikh i strukturnykh kharakteristik asfal'tenosoderzhashchikh dispersnykh sistem: diss. ... kand. tekhn. nauk. Moscow, 2010.

18. Pokonova Yu. V. Khimicheskie reaktsii asfal'tenov [Chemical reactions of asphaltenes]. Leningrad: izd-vo LTI im. Lensoveta. 1984.

19. Posadov I. A., Pokonova Yu. V. Struktura neftyanykh asfal'tenov [Structure of oil asphaltenes]. Leningrad: izd-vo LTI im. Lensoveta. 1977.

20. Shiryaeva R. N., Badikova A. D. i dr. Analiz elementnogo sostava asfal'tenov iz ostatkov neftei Priobskogo i Baklanovskogo mestorozhdenii. Vestnik BashGU. Vol. 22. 2017. No. 2. Pp. 364-366.

Received 22.11.2019. 